\title{
QUALITY OF LIFE OF MENOPAUSAL WOMEN IN RURAL AREA, KEDIRI, EAST JAVA
}

\author{
Aprilia Nurtika Sari, Nining Istighosah \\ Diploma Program in Midwifery, School of Health Sciences \\ Dharma Husada, Kediri, East Java
}

\begin{abstract}
Background: Menopause is a physiological process in women's life. Menopause and its complications could disturb the sense of well-being and health and affect the quality of life. During menopausal transition, there is a lot of fluctuation in the hormone levels, and thus women may experience many symptoms and conditions. This study aimed to examine the quality of life of menopausal women in rural area, Kediri, East Java.

Subject and Method: This was descriptive study conducted at Bangkok village, Gurah, Kediri, East Java, from June to July 2019. A total of 50 menopausal women were selected by purposive sampling. The dependent variable was quality of life. Data on quality of life were obtained by Hilditch \& Bener instrument. The data were analyzed descriptively.

Results: Percents of the sample who experienced symptoms of menopause on vasomotor aspect from mild, moderate, to severe (in percent) were as followed: hot sensation on the face to the neck (56\%; 32\%; 12\%), night sweat (50\%; 40\%; 10\%), and excessive sweating (52 \%; 36\%; 12\%). Symptoms of psychosocial aspect: always wanting to be alone $(58 \% ; 36 \% ; 6 \%)$, sad without cause $(68 \% ; 28 \% ; 4 \%)$, and feeling anxious at all times (35\%; 28\%; $2 \%)$. Symptoms of physical aspect: back pain, neck, and head $(76 \%$; $16 \% ; 8 \%)$, difficulty sleeping (52\%; 7\%; 14\%), weight gain $(60 \% ; 30 \% ; 10 \%)$, decreased ability physical (46\%; 40\%; 14\%), and low back/lower back pain (30\%; 56\%; 14\%). Symptoms of sexual aspect: decreased sexual desire (52\%; 34\%; 14\%), vaginal dryness $(62 \% ; 26 \% ; 12 \%)$, and tend to avoid sexual relations with a husband $(60 \% ; 12 \% ; 28 \%)$. The quality of life scores based on the MENQOL parameter from the smallest to highest were as followed: psychosocial aspect (Mean $=0.44 ; \mathrm{SD}=1.26$ ), physical aspect (Mean= $0.519 ; \mathrm{SD}=1.34)$, vasomotor aspect $(\mathrm{Mean}=0.68 ; \mathrm{SD}=1.50)$ followed by the sexual aspect (Mean=0.71; $\mathrm{SD}=1.46)$.

Conclusion: Menopausal women in rural areas consider menopause to be normal but in reality they experience anxiety or depression if symptoms interfere with their physical and psychological conditions.
\end{abstract}

Keywords: menopause, symptoms, quality of life, rural

\section{Correspondence:}

Aprilia Nurtika Sari. Diploma Program in Midwifery, School of Health Sciences Dharma Husada, Kediri, East Java. Email: aprilia.ns0486@gmail.com. Mobile: +628563651556. 